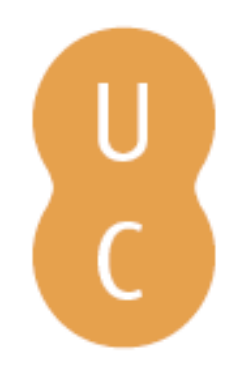

\title{
nombalina
}

\section{O retrato gravado de Carlos Seixas: uma hipótese de interpretação}

\author{
Autor(es): $\quad$ Pimentel, António Filipe \\ Publicado por: Imprensa da Universidade de Coimbra \\ URL \\ persistente: URI:http://hdl.handle.net/10316.2/32521 \\ DOI: $\quad$ DOI:http://dx.doi.org/10.14195/978-989-26-0409-1_3
}

Accessed : $\quad$ 26-Apr-2023 16:21:43

A navegação consulta e descarregamento dos títulos inseridos nas Bibliotecas Digitais UC Digitalis, UC Pombalina e UC Impactum, pressupõem a aceitação plena e sem reservas dos Termos e Condições de Uso destas Bibliotecas Digitais, disponíveis em https://digitalis.uc.pt/pt-pt/termos.

Conforme exposto nos referidos Termos e Condições de Uso, o descarregamento de títulos de acesso restrito requer uma licença válida de autorização devendo o utilizador aceder ao(s) documento(s) a partir de um endereço de IP da instituição detentora da supramencionada licença.

Ao utilizador é apenas permitido o descarregamento para uso pessoal, pelo que o emprego do(s) título(s) descarregado(s) para outro fim, designadamente comercial, carece de autorização do respetivo autor ou editor da obra.

Na medida em que todas as obras da UC Digitalis se encontram protegidas pelo Código do Direito de Autor e Direitos Conexos e demais legislação aplicável, toda a cópia, parcial ou total, deste documento, nos casos em que é legalmente admitida, deverá conter ou fazer-se acompanhar por este aviso.

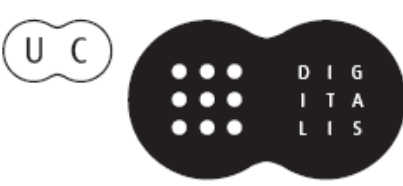




\section{J. M. PEDROSA CARDOSO}

Coordenação

J. M. PEDROSA CARDOSO • ANTÓNIO FILIPE PIMENTEL MANUEL CARLOS DE BRITO • JOSÉ LÓPEZ-CALO JOSÉ EDUARDO MARTINS • ABÍLIO QUEIRÓS

Autores

\section{Carlos Seixas, \\ de Coimbra}

Ano Seixas

Exposição Documental

Coimbra I mprensa da Universidade $\quad 2004$ 
(Página deixada propositadamente em branco) 
J. M. PEDROSA CARDOSO

Coordenação

J. M. PEDROSA CARDOSO • ANTÓNIO FLLIPE PIMENTEL

MANUEL CARLOS DE BRITO • JOSÉ LÓPEZ-CALO

JOSÉ EDUARDO MARTINS • ABÍLIO QUEIRÓS

Autores

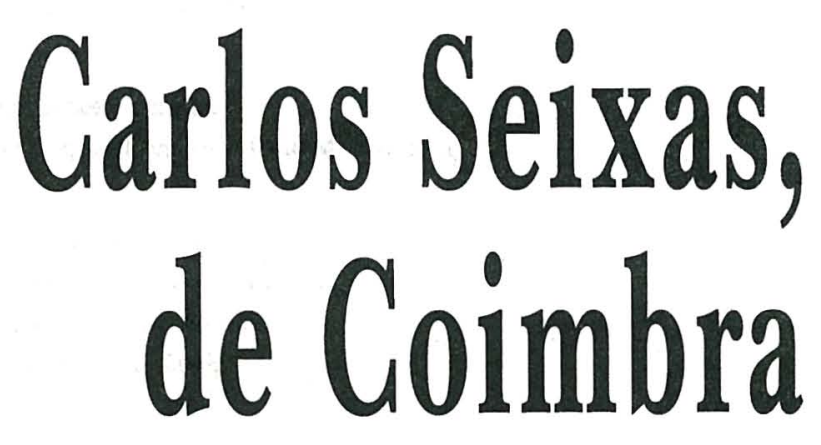

Ano Seixas

Exposição Documental

Coimbra - Imprensa da Universidade $\quad 2004$ 


\section{Coordenação editorial}

Imprensa da Universidade de Coimbra

\section{Concepção gráfica}

António Barros

\section{Paginação}

Victor Hugo Fernandes

\section{Créditos fotográficos}

p. 98 José Manuel Vasconcellos, p. 99 e 100 Varela Pécurto

\section{Execução gráfica}

Imprensa de Coimbra, Lda.

Couraça dos Apóstolos, 126

3000-372 Coimbra

\section{ISBN}

972-8704-33-X

\section{Depósito Legal}

\section{$218421 / 04$}

(C) 2004, Imprensa da Universidade de Coimbra

Obra publicada com o patocínio do GRUPO AMORIM:

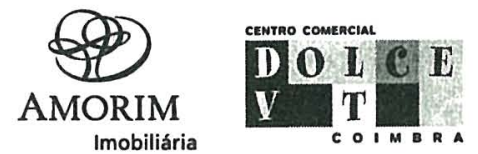

Apoio de:

Reitoria da Universidade de Coimbra

Biblioteca da Universidade de Coimbra

Arquivo da Universidade de Coimbra

Faculdade de Letras da Universidade de Coimbra 


\title{
O Retrato gravado de Carlos Seixas: UMA HIPÓTESE DE INTERPRETAÇÃO
}

\author{
António Filipe Pimentel \\ (Universidade de Coimbra)
}

No panorama relativamente austero da representação figurativa de personalidades destacadas do meio cultural português da primeira metade do século XVIII (ainda assim novidade iconográfica introduzida pelo ambiente renovador do reinado de D. João V) avulta, desde logo pelas imprecisões que ainda rodeiam a sua biografia, nimbada pela aura de celebridade que o rodeou em vida ("monstro da natureza" lhe chamou Barbosa Machado, ao coligir a sua biografia, onde alude indirectamente ao conhecido episódio com Scarlatti), a bela gravura representativa de Carlos Seixas ${ }^{(1)}$. E o caso não é para menos: a estampa (de $212 \times 164 \mathrm{~mm}$, nos exemplares completos), não datada, foi realizada sobre desenho de Francisco Veira (Lusitano), mas em Paris, por Jean Daullé, graveur du Roy, discípulo de Rigaud na Académie e pura e simplesmente um dos melhores e mais célebres gravadores franceses do século XVIII (isto é, do mundo), famoso justamente pelos seus magníficos retratos, e que daria à galeria das personagens célebres portuguesas uma outra importante contribuição: a efígie do sumptuoso grão-mestre da Ordem Soberana e Militar de Malta, Frei

(1) Segundo Ernesto Vieira, no Diccionario Biographico de Músicos Portuguezes, existem duas versões diferentes desta gravura, das quais, todavia, não fornece descrições (vol. II, p. 292). Ernesto Soares, que menciona a indicação de E. V., refere contudo somente a estampa que nos ocupa, única actualmente conhecida e, aliás, de grande raridade (História da Gravura Artística em Portugal, vol. I, p. 202). 
Manuel Pinto de Vilhena. Esta, todavia, datada de 1744, enquanto, ao invés, não é possível saber exactamente quando o retrato de Seixas foi realizado.

Ora, a gravura que nos importa ostenta uma iconografia peculiar: o artista português é figurado em traje alegórico de sabor antiquizante, pendente do pescoço a venera da Ordem de Cristo (de que era cavaleiro professo, além de contador do Mestrado da Ordem de Santiago), como indicador das honras que o rodearam em vida e cercado do conjunto de adereços que o identificam como músico inspirado: o cravo, a que se apoia e sobre cujo tampo inscreve, com a destra, num livro de música, porventura uma das setecentas tocatas que Machado atribui ao seu prodigioso estro criativo, enquanto, com a sinistra, sustenta a lira alada da sua ubérrima inspiração, divisando-se em fundo a tubagem de um órgão. Sobre a fronte, uma estrela de oito pontas alude, em referência humanística, à consonância entre a glória que a inspiração musical lhe alcançara e as virtudes que o ornaram em vida, remetendo para a legenda inferior subsistente nos exemplares completos (Hanc merui citharam stellis radiantibus addi: Dissona nec vitæ moribus illa fuit $\left.{ }^{(2)}\right)$, inscrevendo-se na moldura oval que circunda a composição os dizeres JOSEPHUS ANTONIUS CARLOS \& SEIXAS, vixit annos 38. obiit die 25 augusti anno 1742.

Nestas circunstâncias (e mesmo descontando a legenda identificadora, hipoteticamente feita apenas para a estampa), não parece poder aceitar-se que esta tenha por base um retrato realizado em vida do artista (por Vieira Lusitano), por encomenda naturalmente do próprio, com os tradicionais intuitos de dignificação social, como os que se conhecem de Manuel de Azevedo Fortes, João Frederico Ludovice ou Carlos Mardel (para referir justamente exemplos do círculo régio na esfera das belas-artes), devidos aos melhores pincéis ao serviço da Corte do Magnânimo e onde os retratados, além de um ou outro atributo distintivo da sua actividade, como era de uso, se apresentam como desejariam ser recordados pela posteridade, no esplendor do seu estatuto social, com recurso ao usual aparato do retrato áulico setecentista: da pose teatral à qualidade dos adereços (rico traje cortesão, opulento mobiliário, aparatosos trechos de arquitectura, sumptuosos panejamentos). Inversamente, tudo no retrato de Seixas aponta

(2) "Mereci que à minha cítara se acrescentassem os raios das estrelas. / E delas não foram dissonantes a vida nem os costumes" (agradecemos, tanto a tradução como a interpretação do sentido do texto latino à amizade c cortesia do Senhor Doutor Aníbal Pinto de Castro). 
para uma representação póstuma, celebrativa, onde o artista surge já envolto na aura da eternidade, a que o haviam guindado a um tempo o seu talento raro e a singularidade das suas virtudes.

É aqui que se perfila, como plausível, a hipótese de que o retrato original de Vieira Lusitano (a óleo ou desenhado) tenha sido realizado com destino às solenes exéquias celebradas pelos Eremitas de Santo Agostinho no seu Convento da Graça de Lisboa, ao completar-se um mês sobre a morte do artista, função à qual, como relata Barbosa Machado, assistiu grande parte da nobreza da Corte. Exéquias que obviamente não foram do livre alvedrio da comunidade monástica (antes consequência, por certo, de um movimento colectivo de homenagem gerado no interior dos círculos cultos da Corte joanina - donde o grande concurso de nobreza -, muito provavelmente, como em tantos casos sucedeu, com o patrocínio, directo ou indirecto do monarca) e cujo carácter celebrativo e distanciamento temporal em relação aos rituais específicos do enterro, eram utilizados, pela sociedade e pela cultura do Barroco, justamente para a organização de pomposas cerimónias evocativas, objecto de uma decoração ad hoc do templo em que se realizavam, onde pontificava a essa, ou castrum doloris ornada, por regra, com o retrato do finado. É o que parece indicar, aliás, a única menção, na tarja da moldura (que bem poderia constar, assim, do quadro original, precisamente oval nos exemplos conhecidos), ao tempo de vida e à data da morte (omitindo o nascimento).

$\mathrm{E}$ é esse mesmo movimento colectivo, não somente da nobreza, mas da gente letrada em ascensão, cuja actividade cultural (e científica) se centrava nas academias (não apenas a da História, mas numerosas outras, de índole privada, disseminadas pelo País inteiro - e mesmo além) que povoam o reinado do Magnânimo e que, em tempo de luzes, se aplicava na classificação, organização e ilustração do universo conhecido, organizando vastas colecções iconográficas, o destinatário lógico de uma gravura aberta em Paris, não se sabe quantos anos depois (seguramente poucos) e de que os escassos exemplares conhecidos se integram ainda hoje, justamente, em antigas colecções iconográficas. E talvez não seja temerário, uma vez mais, vislumbrar nesse recurso a um prestigioso artista da Corte de Luís XV Daullé, graveur du Roy - e no necessário transporte para Paris do original de Vieira Lusitano, a mão oculta do régio protector do próprio Seixas e dos seus circuitos diplomáticos, aplicados como nunca antes ao serviço de uma permanente dinâmica artística que funcionava também como instrumento 
politico de propaganda aquém e além fronteiras. E nenhum palco melhor do que Paris para uma afirmação de prestígio de alcance internacional - é, aliás, seguramente, este conjunto de ideias (e de ambições) o que se perfila por detrás da encomenda, ao mesmo gravador, do sumptuoso retrato de Frei Manuel Pinto de Vilhena, o opulento príncipe-prelado.

Documento algum apoia, certamente, a hipótese que aqui se configura. Mas parece certo ser bastante difícil de compreender a produção de semelhante gravura - nas suas características técnicas e iconográficas - no exterior do conjunto de interrelações que atrás se procurou enunciar.

\section{BibLIOGRAFIA}

BÉNezrt, E. - Dictionaire critique et documentaire dês peintres, sculpteurs, dessinateurs et graveurs, tome 4, Gründ, 1999.

Machado, Diogo Barbosa - Bibliotheca Luzitana, tomo IV, Lisboa, Officina Patriarcal de Luiz Ameno, 1759.

Sonres, Ernesto - História da Gravura Artística em Portugal, vol. I, Lisboa, Livraria Sam Carlos, 1971.

VIEIRA, Ernesto - Diccionario Biographico de Músicos Portuguezes, vol. II, Lisboa, s.n., 1900. 
(Página deixada propositadamente em branco) 


\section{Série}

\section{Documentos}

Imprensa da Universidade de Coimbra

Coimbra University Press

2004

- U

C • 